\title{
Ralph C. Russell, 1896-1964
}

by J. L. Parker, Gilbert Plains, Manitoba

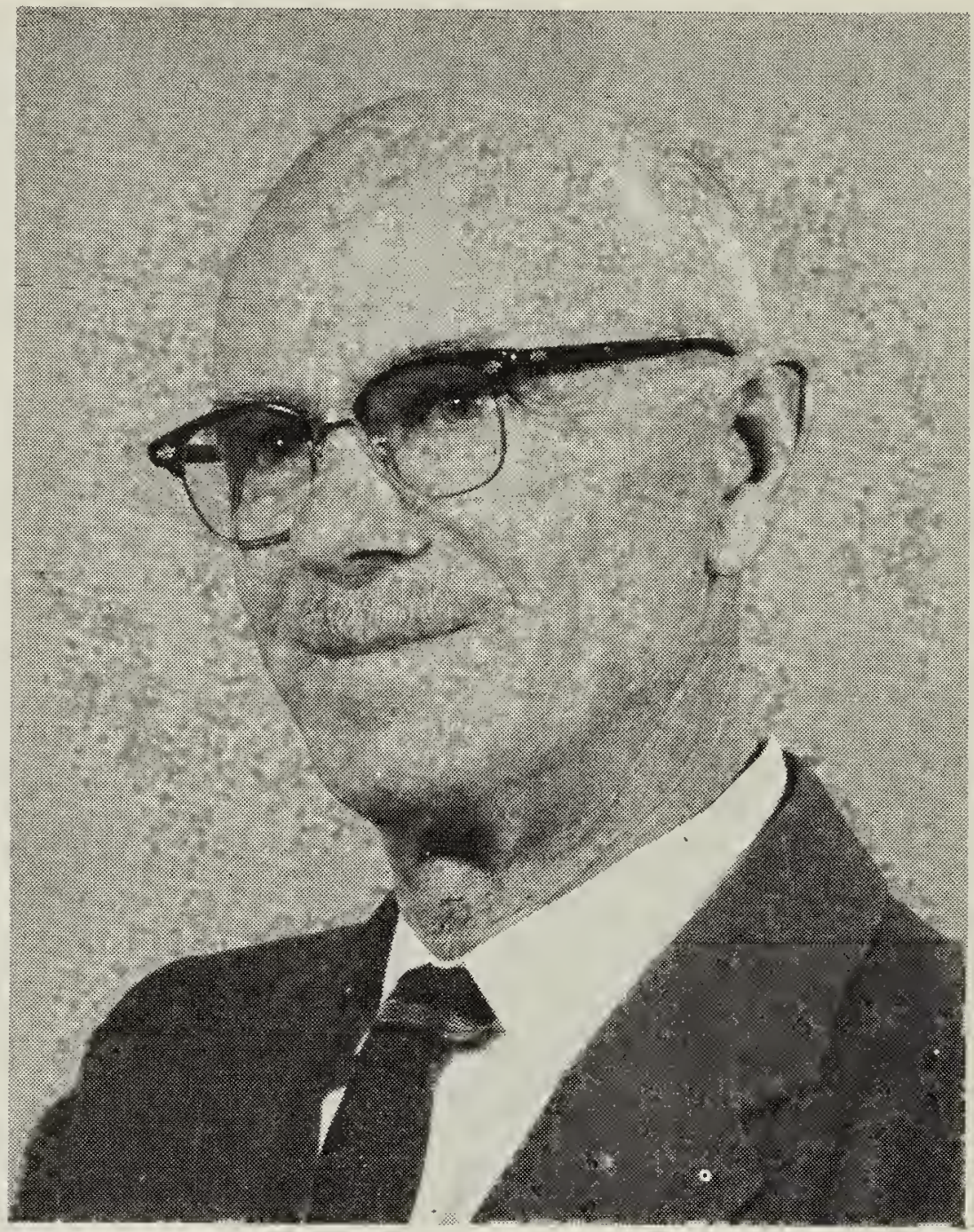

Dr. R. C. Russell was born at Charing Cross, Ontario, in 1896, and later came with his parents to a farm near Kelliher, Saskatchewan. After training as a pilot with the R.F.C. in 1918, he entered the University of Saskatchewan graduating with the B.S.A. in 1924, and M.Sc. in 1926. His Ph.D. degree was received in 1934 at the University of Toronto. Dr. Russell joined the staff of the Federal Laboratory of Plant Pathology at Saskatoon in 1923 and was classified as Plant Pathologist in 1925; he held this position until his retirement in 1961. He lectured on the taxonomy of vascular plants at the University from 1938 to 1947 . His research projects included work on takeall root rot of wheat and barley and loose smut of barley; while experimenting with loose smut Dr. Russell developed the hot water treatment for barley seed. He acted as scientific adviser to the Kelvington seed barley project.

Dr. Russell was a charter member of the Canadian Phytopathological Society and served as secretary- treasurer for two years, 1945-47. He was a member of the Agricultural Institute of Canada and a charter member of the Saskatchewan Institute of Agrologists. The Canadian Seed Growers' Association made him an honorary life member in 1963.

In addition to his contributions to agriculture, Dr. Russell collected a fine library of Canadiana and was author of The Carlton Trail, 1954, and numerous articles; he also gave lectures on early Canadian history. He was co-author, with the late W. P. Fraser, of the List of the flowering plans, ferns and fern allies of Saskatchewan, 1937, which he revised in 1944 and 1954. He was also an expert photographer and his photographs may be seen in the National Museum's collection of Outstanding Wild Life Photographs.

He was a man of many talents, all of which he freely used for our venefit. When he died in Saskatoon on July 15, 1964, we lost a great scholar and a kindly gentleman. 